\title{
Dysregulation of KRAS signaling in pancreatic cancer is not associated with $K R A S$ mutations and outcome
}

\author{
RADMILA LEMSTROVA ${ }^{1}$, VERONIKA BRYNYCHOVA ${ }^{2,3}$, DAVID J. HUGHES ${ }^{4}$, VIKTOR HLAVAC ${ }^{2,3}$, \\ PAVEL DVORAK ${ }^{5}$, JOANNE E. DOHERTY $^{6}$, HELENA A. MURRAY ${ }^{6}$, MARTIN CROCKARD $^{6}$, \\ MARTIN OLIVERIUS ${ }^{7}$, JAN HLAVSA $^{8}$, EVA HONSOVA $^{9}$, JAN MAZANEC $^{10}$, ZDENEK KALA $^{8}$, \\ MARTIN LOVECEK ${ }^{11}$, ROMAN HAVLIK ${ }^{11}$, JIRI EHRMANN ${ }^{12,13}$, ONDREJ STROUHAL ${ }^{1}$, \\ PAVEL SOUCEK $^{2,3}$, BOHUSLAV MELICHAR ${ }^{1,13}$ and BEATRICE MOHELNIKOVA-DUCHONOVA ${ }^{1,2}$
}

\footnotetext{
${ }^{1}$ Department of Oncology, Faculty of Medicine and Dentistry, Palacky University Olomouc and University Hospital Olomouc,

77147 Olomouc; ${ }^{2}$ Department of Toxicogenomics, National Institute of Public Health, 10042 Prague;

${ }^{3}$ Biomedical Centre, Faculty of Medicine in Pilsen, Charles University in Prague, 32300 Pilsen, Czech Republic;

${ }^{4}$ Department of Physiology and Centre for Systems Medicine, Royal College of Surgeons in Ireland, Dublin 2, Republic of Ireland; ${ }^{5}$ Department of Biology, Faculty of Medicine in Pilsen, Charles University 32300 Pilsen, Czech Republic;

${ }^{6}$ Randox Laboratories Ltd., Crumlin, BT29 4QY, Northern Ireland, UK ${ }^{7}$ Department of Transplantation Surgery,

Institute of Clinical and Experimental Medicine, 14021 Prague; ${ }^{8}$ Department of Surgery, University Hospital and Medical Faculty, Masaryk University, 62500 Brno; ${ }^{9}$ Department of Clinical and Transplantation Pathology, Institute of Clinical and Experimental Medicine, 14021 Prague; ${ }^{10}$ Department of Pathology, University Hospital and Medical Faculty, Masaryk University, 62500 Brno; ${ }^{11}$ Department of Surgery I, Faculty of Medicine and Dentistry,

Palacky University Olomouc and University Hospital Olomouc; ${ }^{12}$ Department of Clinical and Molecular Pathology and Laboratory of Molecular Pathology, Faculty of Medicine and Dentistry, Palacky University, 77147 Olomouc;

${ }^{13}$ Institute of Molecular and Translational Medicine, Faculty of Medicine and Dentistry, Palacky University, 77900 Olomouc, Czech Republic
}

Received January 10, 2017; Accepted June 21, 2017

DOI: $10.3892 / \mathrm{ol} .2017 .6946$

\begin{abstract}
Pancreatic ductal adenocarcinoma (PDAC) is a tumor with a poor prognosis, and no targeted therapy is currently available. The aim of the present study was to investigate the prognostic significance of the expression of $\mathrm{V}-\mathrm{Ki}$-ras2 Kirsten rat sarcoma viral oncogene homolog (KRAS), downstream signaling pathway genes and the association with clinical characteristics in PDAC patients undergoing radical surgery. Tumors and adjacent non-neoplastic pancreatic tissues were examined in 45 patients with histologically verified PDAC. KRAS and B-Raf proto-oncogene, serine/threonine kinase $(B R A F)$ gene mutation analysis was performed using the $K R A S / B R A F /$ phosphatidylinositol-4,5-bisphosphate 3 -kinase catalytic subunit $\alpha$ array. The transcript profile
\end{abstract}

Correspondence to: $\operatorname{Dr}$ Beatrice Mohelnikova-Duchonova, Department of Toxicogenomics, National Institute of Public Health, Srobarova 48, 10042 Prague 10, Czech Republic

E-mail: mohelnikova@szu.cz

Key words: pancreatic ductal adenocarcinoma, KRAS, gene expression, mutation, overall survival of 52 KRAS downstream signaling pathway genes was assessed using quantitative-polymerase chain reaction. KRAS mutation was detected in $80 \%$ of cases. The genes of four signaling pathways downstream of KRAS, including the phosphoinositide 3-kinase/3-phosphoinositide-dependent protein kinase $1 / \mathrm{V}$-akt murine thymoma viral oncogene homolog 1, RAL guanine nucleotide exchange factor, Ras and $\mathrm{Rab}$ interactor $1 / A B L$ proto-oncogene-1, non-receptor tyrosine kinase, and RAF proto-oncogene serine/threonine-protein kinase/mitogen-activated protein kinase pathways, exhibited differential expression in PDAC compared with that in the adjacent normal tissues. However, no significant differences in expression were evident between patients with KRAS-mutated and wild-type tumors. The expression of KRAS downstream signaling pathways genes did not correlate with angioinvasion, perineural invasion, grade or presence of lymph node metastasis. Additionally, the presence of KRAS mutations was not associated with overall survival. Among the KRAS downstream effective signaling pathways molecules investigated, only v-raf-1 murine leukemia viral oncogene homolog 1 expression was predictive of prognosis. Overall, KRAS mutation is present in the majority of cases of PDAC, but is not associated with changes in the expression of KRAS downstream signaling pathways and the clinical outcome. This may partly explain the failure of KRAS-targeted therapies in PDAC. 


\section{Introduction}

Pancreatic ductal adenocarcinoma (PDAC; Online Mendelian Inheritance in Man no. 260350) ranks fourth in the leading causes of cancer-associated mortality in Western countries (1). Despite diagnostic and therapeutic advances, the prognosis of PDAC remains poor. Only $20 \%$ of patients present with potentially resectable disease at the time of diagnosis, while due to the high propensity for tumor recurrence, the 5-year overall survival (OS) rate in patients undergoing surgery with radical intent is usually $<25 \%$. Although a number of prospective clinical trials have demonstrated that adjuvant systemic therapy improves the patient outcome following surgery, adjuvant chemotherapy appears to be effective only in a minority of patients, and the majority of the patients ultimately succumb to the disease. The prognosis of metastatic patients is extremely poor, with a median OS time of $<1$ year (2). Consequently, novel regimens of adjuvant treatment are being investigated and there is currently no definitive standard of adjuvant therapy.

In PDAC, mutations in the V-Ki-ras2 Kirsten rat sarcoma viral oncogene homolog $(K R A S)$ gene occur in $75-90 \%$ of cases, representing the most frequent, as well as the earliest, genetic alteration. KRAS mutations, specifically in codons 12 and 13, lead to constitutive activation of downstream signaling pathways that are important for tumor initiation, development and spread $(3,4)$. KRAS signaling is highly complex and dynamic, with various downstream effector pathways interconnected at different levels by cross-signaling and feedback loops (5). The four major KRAS downstream pathways reported in PDAC are RAF proto-oncogene serine/threonine-protein kinase (RAF)/mitogen-activated protein kinase (MAPK), phosphoinositide 3-kinase (PI3K)/3-phosphoinositide-dependent protein kinase 1 (PDK1)/ABL proto-oncogene-1, non-receptor tyrosine kinase (ABL), RAL guanine nucleotide exchange factor, and Ras and Rab interactor 1 (RIN1)/ABL pathways (Fig. 1) (6-10). This multiplicity of downstream pathways may partly explain the failure of existing efforts to target epidermal growth factor receptor, KRAS or serine/threonine-protein kinase B-raf (BRAF) using specific inhibitors, underlining the complexity of genetic changes and the resistance of the cancer cells.

The aim of the present study was to assess the association between gene expression from the four major KRAS-effective pathways in PDAC and the clinical features of the patients, and to evaluate the potential predictive and prognostic significance.

\section{Materials and methods}

Patients. A cohort of 45 consecutive patients with PDAC who underwent surgery with curative intent was recruited from two oncology centers in the Czech Republic (Institute of Clinical and Experimental Medicine, Prague; and University Hospital, Masaryk University, Brno, Czech Republic) between August 2008 and January 2012. Inclusion criteria were: i) Adult operable patients with suspected pancreatic carcinoma based on clinical imaging methods; ii) patients who provided informed consent; and iii) pancreatic carcinoma diagnosis was verified by collaborating pathologist. None of the patients had received prior chemotherapy. Characteristics of the patient cohort are summarized in Table I. The tissue specimen collection and processing, and the data retrieval were as described previously (11).

All patients signed an informed consent form, in accordance with the requirements for ethical approval, which was provided by the Institutional Review Boards of the Institute of Clinical and Experimental Medicine and University Hospital, Masaryk University, Brno.

Isolation of nucleic acids and cDNA synthesis. Tissue samples were homogenized and total RNA and DNA was isolated as previously described $(12,13)$. cDNA was synthesized using $0.5 \mu \mathrm{g}$ total RNA and characterized as previously described (14). cDNA was then pre-amplified by TaqMan ${ }^{\circledR}$ PreAmp Master mix to enrich the specific targets for gene expression analysis using TaqMan Gene Expression assays (Life Technologies; Thermo Fisher Scientific, Inc., Waltham, MA, USA) (Table II). The cDNA pre-amplification was performed with $5 \mu \mathrm{l}$ cDNA using 14 pre-amplification cycles $\left(10 \mathrm{~min}\right.$ at $95^{\circ} \mathrm{C}$ and 14 cycles of $15 \mathrm{sec}$ at $95^{\circ} \mathrm{C}$ ), and the pre-amplification uniformity of cDNA was checked according to the procedure recommended by the manufacturer (Thermo Fisher Scientific, Inc.).

Quantitative polymerase chain reaction ( $q P C R)$. qPCR was performed using the ViiA7 Real-Time PCR system using TaqMan Gene Expression assays (Table I), with optimized primer and probe sets and TaqMan Gene Expression Master mix (Thermo Fisher Scientific, Inc.). Processing of precursor 4, S. cerevisiae, homolog of, mitochondrial ribosomal protein L19, E74-like factor 1 and eukaryotic translation initiation factor $2 \mathrm{~B}$ subunit 1 were used as reference genes for studies of gene expression in human pancreatic carcinoma based on our previously published data (15). Determination of transcript levels was performed exactly as previously described (10) and the qPCR study adhered to the Minimum Information for Publication of Quantitative Real-Time PCR Experiments Guidelines (16).

KRAS and BRAF mutation status. KRAS and BRAF gene mutation analysis was performed using the $K R A S / B R A F /$ phosphatidylinositol-4,5-bisphosphate 3-kinase catalytic subunit $\alpha$ (PIK3CA) (KBP) Array (EV3799A/B; Randox Laboratories Ltd., Crumlin, Northern Ireland) according to the manufacturer's instructions. The assay is based on a combination of multiplex PCR and biochip array hybridization for high discrimination between multiple wild-type and mutant DNA regions in the KRAS (mutations in codons 12, 13 and 61), BRAF (V600E mutation) and PIK3CA (mutations in codons 542, 545 and 1,047) genes. Providing there are enough copies of DNA present, $\sim 1 \%$ of mutants can readily be detected in a background of wild-type genomic DNA. A unique primer set is designed for each mutation target (and control), which will hybridize to a complementary discrete test region (DTR) on the biochip array. Each DTR corresponds to a particular mutation target. One of the target-specific primers in each pair contains a biotin label, which on addition of streptavidin-horseradish peroxidase conjugate permits chemiluminescence detection of hybridized products on the biochip array. Dedicated software processes produced automatic results. 


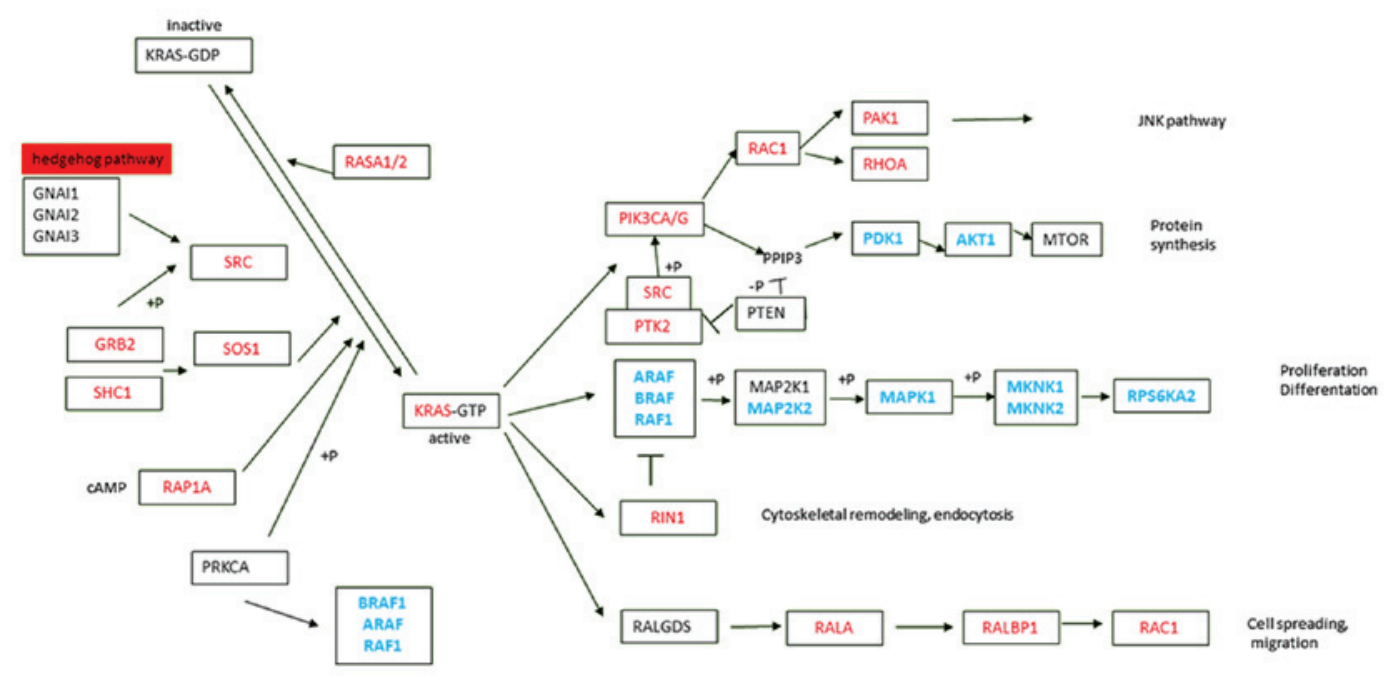

Figure 1. Dysregulation of KRAS signaling pathway in PDAC tumors compared with that in the paired adjacent non-malignant tissues. KRAS pathway map noting the differentially expressed genes in PDAC tumors compared with those in adjacent non-malignant tissues. Genes overexpressed in tumor tissue are in red, while downregulated genes are in blue. Genes not exhibiting differential expression are in black. KRAS, KRAS proto-oncogene, GTPase; PDAC, pancreatic ductal adenocarcinoma.

Statistical analysis. Differences in gene expression profiles between tumor and paired non-neoplastic control tissues and between wild-type and KRAS-mutated samples were evaluated using the RT ${ }^{2}$ Profiler PCR Assay Data Analysis v3.5 program (Qiagen $\mathrm{GmbH}$, Hilden, Germany). This gene expression analysis suite performs fold-change calculations from raw quantification cycle values for reference and target genes based on the $\Delta \Delta \mathrm{Cq}$ method described by Livak and Schmittgen (17), and enables hierarchical clustering of gene expression profiles between the compared groups of patients and data. Differences in intratumoral gene expression levels between patients stratified by clinical data were evaluated by the Kruskal-Wallis test.

OS was defined as the time between the date of surgery and all-cause mortality. Surviving patients were censored at the last follow-up in December 2015. Patients were divided into two groups by the median intratumoral gene expression levels of individual genes and the survival functions were computed by the Kaplan-Meier method, with statistical significance evaluated by the Breslow test using SPSS v16.0 (SPSS, Inc., Chicago, IL, USA).

$\mathrm{P}<0.05$ was considered to indicate a statistically significant difference. All P-values are departures from two-sided tests. The correction for multiple testing was applied according to the Bonferroni and the false discovery rate (FDR) methods.

\section{Results}

Study population. The study was performed on 45 patients with resected (R0 resection in $>90 \%$ of cases) PDAC who had not received any prior neoadjuvant therapy. Overall, $80 \%$ (36/45) of patients harbored KRAS mutations in the DNA of the tumor tissue, while $B R A F$ mutations were not found in any sample (Table II). The majority of patients $(76 \%$; $n=34)$ received adjuvant chemotherapy consisting of nucleoside analogs (gemcitabine and/or 5-fluorouracil).

The median OS time was 23.7 months, with $18 \%$ of patients $(n=8)$ alive at the time of data cut off (December 2015).
Table I. Characteristics of the patient cohort.

Variables 20

Mean age (range), years

$63.9(46-80)$

Sex, $\mathrm{n}(\%)$

Male

$20(44.4)$

Female

$25(55.6)$

Histological grade, $\mathrm{n}(\%)$

$\mathrm{G} 1+\mathrm{G} 2$ (well to moderate)

$30(66.7)$

$\mathrm{G} 3+\mathrm{G} 4$ (poor)

Primary tumor extent of invasion, $\mathrm{n}(\%)$

pT1 tumor limited to the pancreas $\leq 2 \mathrm{~cm}$

pT2 tumor limited to the pancreas $>2 \mathrm{~cm}$

$39(86.7)$

pT3 tumor extending beyond the pancreas

pN1

Not assessed

Not assessed

Deceased

8 (17.8) onine kinase; KRAS, KRAS proto-oncogene, GTPase. 
Table II. List of TaqMan gene expression assays used in the study.

\begin{tabular}{|c|c|c|}
\hline Gene abbreviation & Gene name & Assay ID \\
\hline$A K T 1$ & V-akt murine thymoma viral oncogene homolog 1 & Hs00178289_m1 \\
\hline$A K T 2$ & V-akt murine thymoma viral oncogene homolog 2 & Hs01086102_m1 \\
\hline$A R A F$ & V-raf murine sarcoma viral oncogene homolog 1 & Hs00176427_m1 \\
\hline$B R A F$ & V-raf murine sarcoma viral oncogene homolog B1 & Hs00269944_m1 \\
\hline GRB2 & Growth factor receptor-bound protein 2 & Hs00257910_s1 \\
\hline$G S K 3 B$ & Glycogen synthase kinase $3-\beta$ & Hs00275656_m1 \\
\hline$K R A S$ & V-ki-ras2 Kirsten rat sarcoma viral oncogene homolog & Hs00364284_g1 \\
\hline$M A P 2 K 1$ & Mitogen-activated protein kinase kinase 1 & Hs00983247_g1 \\
\hline$M A P 2 K 2$ & Mitogen-activated protein kinase kinase 2 & Hs04194606_gH \\
\hline$M A P 2 K 7$ & Mitogen-activated protein kinase kinase 7 & Hs00178198_m1 \\
\hline$M A P 3 K 1$ & Mitogen-activated protein kinase kinase kinase 1 & Hs00394890_m1 \\
\hline MAP3K2 & Mitogen-activated protein kinase kinase kinase 2 & Hs01109981_m1 \\
\hline$M A P 3 K 4$ & Mitogen-activated protein kinase kinase kinase 4 & Hs00245958_m1 \\
\hline$M A P 3 K 7$ & Mitogen-activated protein kinase kinase kinase 7 & Hs01105682_m1 \\
\hline$M A P K 1$ & Mitogen-activated protein kinase 1 & Hs01046830_m1 \\
\hline MAPK 10 & Mitogen-activated protein kinase 10 & Hs00373455_m1 \\
\hline MAPK14 & Mitogen-activated protein kinase 14 & Hs01051152_m1 \\
\hline$M A P K 3$ & Mitogen-activated protein kinase 3 & Hs00946872_m1 \\
\hline$M A P K 7$ & Mitogen-activated protein kinase 7 & Hs00611114_g1 \\
\hline$M A P K 8$ & Mitogen-activated protein kinase 8 & Hs00177083_m1 \\
\hline MAPK9 & Mitogen-activated protein kinase 9 & Hs00177102_m1 \\
\hline$M K N K 1$ & Mitogen-activated protein kinase-interacting serine/threonine kinase 1 & Hs00374376_m1 \\
\hline$M K N K 2$ & Mitogen-activated protein kinase-interacting serine/threonine kinase 2 & Hs01046586_g1 \\
\hline MTOR & Mechanistic target of rapamycin & Hs00234508_m1 \\
\hline$P A K 1$ & p21 protein-activated kinase 1 & Hs00176815_m1 \\
\hline PDPK1 & 3-phosphoinositide-dependent protein kinase 1 & Hs00176884_m1 \\
\hline$P I K 3 C A$ & Phosphatidylinositol 3-kinase, catalytic, $\alpha$ & Hs00907966_m1 \\
\hline$P I K 3 C G$ & Phosphatidylinositol 3-kinase, catalytic, $\gamma$ & Hs00277090_m1 \\
\hline$P L K 3$ & Polo-like kinase 3 & Hs00177725_m1 \\
\hline PRKACA & Protein kinase, camp-dependent, catalytic, $\alpha$ & Hs00427274_m1 \\
\hline$P R K C A$ & Protein kinase c, $\alpha$ & Hs00925195_m1 \\
\hline PTEN & Phosphatase and tensin homolog & Hs02621230_s1 \\
\hline$P T K 2$ & Protein-tyrosine kinase, cytoplasmic & Hs01056457_m1 \\
\hline$P T K 2 B$ & Protein-tyrosine kinase $2, \beta$ & Hs01559708_m1 \\
\hline$R A C 1$ & Ras-related C3 botulinum toxin substrate 1 & Hs01025984_m1 \\
\hline$R A F 1$ & V-raf-1 murine leukemia viral oncogene homolog 1 & Hs00234119_m1 \\
\hline$R A L A$ & V-ral simian leukemia viral oncogene homolog A & Hs01564991_g1 \\
\hline$R A L B P 1$ & RalA-binding protein 1 & Hs01034988_g1 \\
\hline$R A L G D S$ & Ral guanine nucleotide dissociation stimulator & Hs00325141_m1 \\
\hline$R A P 1 A$ & Ras-related protein $1 \mathrm{~A}$ & Hs01092205_g1 \\
\hline RASAl & Ras p21 protein activator 1 & Hs00963555_m1 \\
\hline RASA2 & Ras p21 protein activator 2 & Hs01003325_m1 \\
\hline RHOA & Ras homolog gene family, member A & Hs00357608_m1 \\
\hline RIN1 & Ras and rab interactor 1 & Hs00182870_m1 \\
\hline RPS6KA2 & Ribosomal protein S6 kinase, $90-\mathrm{kd}, 2$ & Hs00179731_m1 \\
\hline RPS6KA4 & Ribosomal protein S6 kinase, $90-\mathrm{kd}, 4$ & Hs00177670_m1 \\
\hline RPS6KA5 & Ribosomal protein S6 kinase, $90-\mathrm{kd}, 5$ & Hs01046594_m1 \\
\hline SHCl & SHC transforming protein & Hs01050699_g1 \\
\hline SOS1 & Son of sevenless, Drosophila, homolog 1 & Hs00362316_m1 \\
\hline SOS2 & Son of sevenless, Drosophila, homolog 2 & Hs00412876_g1 \\
\hline$S R C$ & V-src avian sarcoma (Schmidt-Ruppin A-2) viral oncogene & Hs01082238_g1 \\
\hline STAT3 & Signal transducer and activator of transcription 3 & Hs01047580_m1 \\
\hline
\end{tabular}


Table II. Continued.

\begin{tabular}{|c|c|c|}
\hline Gene abbreviation & Gene name & Assay ID \\
\hline$E L F 1^{\mathrm{a}}$ & E74-like factor 1 & Hs00152844_m1 \\
\hline$E I F 2 B 1^{\text {a }}$ & Eukaryotic translation initiation factor $2 \mathrm{~B}$, subunit 1 & Hs00426752_m1 \\
\hline$M R P L 19^{\mathrm{a}}$ & Mitochondrial ribosomal protein 119 & Hs00608519_m1 \\
\hline$P O P 4^{\text {a }}$ & Processing of precursor $4, S$. cerevisiae, homolog of & Hs00198357_ml \\
\hline
\end{tabular}

${ }^{\mathrm{a}}$ Reference genes.

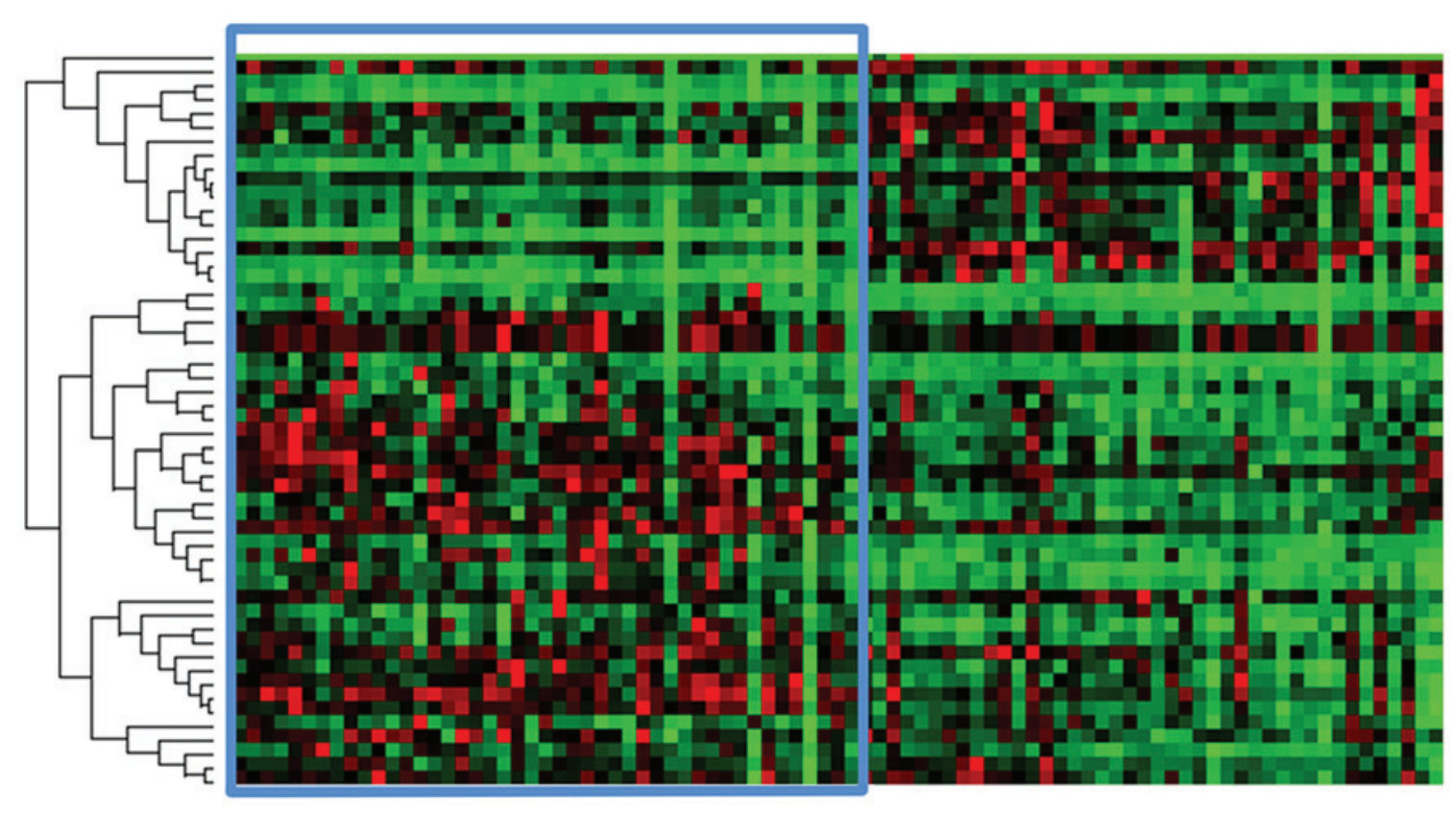

Magnitude of gene expression

Figure 2. Heat map of KRAS proto-oncogene, GTPase signaling pathway expression profile of pancreatic ductal adenocarcinoma. Tumor samples are contained within the blue box on the left and the non-malignant pancreatic tissue samples are shown on the right.

Transcript levels of KRAS signaling pathways genes in $P D A C$. Considering the pivotal role of KRAS oncogene in the integration and transduction of mitogenic and metabolic signals, the transcript levels of 52 genes covering four major pathways downstream of KRAS were measured (Table I). The KRAS pathway was significantly dysregulated in tumors compared with that in adjacent non-malignant pancreatic tissues (Fig. 2; Table III). Significant overexpression of genes of the PI3K/PDK1/AKT, RAL guanine nucleotide exchange factor, and RINI/ABL [phosphatidylinositol 3-kinase, catalytic, $\alpha / \gamma(P I K 3 C A / G)$, p21 protein-activated kinase 1, V-ral simian leukemia viral oncogene homolog A, RalA-binding protein 1, Ras-related $\mathrm{C} 3$ botulinum toxin substrate 1, RINI, protein-tyrosine kinase, cytoplasmic, and $\mathrm{V}$-src avian sarcoma (Schmidt-Ruppin A-2) viral oncogene] pathways were observed, leading to cytoskeletal remodeling, endocytosis, cell spreading and migration (Table III; Fig. 1). By contrast, genes of the $R A F / M A P K$ pathway exhibited significantly lower expression in tumors compared with that in the paired adjacent non-malignant pancreatic tissues (particularly in genes $A R A F, B R A F, V-R A F-1$ murine leukemia viral oncogene homolog 1 (RAF1), mitogen-activated protein kinase kinase, mitogen-activated protein kinase 1 , mitogen-activated protein kinase-interacting serine/threonine kinase 1/2 (MKNK1/2) and ribosomal protein S6 kinase, 90-kd, 2. All these results remained significant after FDR adjustment for multiple testing and the majority remained significant after Bonferroni correction (Table III; Fig. 1).

However, no association between KRAS downstream signaling pathway gene expression and tumor characteristics, including tumor size, grade, angioinvasion, lymph node metastasis or perineural invasion, passed the significance threshold of the Bonferroni test.

Impact of KRAS mutation status on transcript levels of target genes. From the $80 \%$ of tumor samples with KRAS mutations, the most common mutation, KRAS $S^{\mathrm{G} 12 \mathrm{D}}$, was present in $33 \%(\mathrm{n}=15)$ of the tumors. Only 1 tumor was found with a mutation in codon 13 , and 2 cases with a mutation in codon 61 (Table II).

Patients divided by the KRAS mutation status significantly differed in terms of the gene expression of 5 of 
Table III. Dysregulation of KRAS pathway genes in pancreatic ductal adenocarcinoma tumors in comparison to paired adjacent non-malignant tissues.

\begin{tabular}{|c|c|c|c|}
\hline Gene & Fold-change (tumor vs. non-malignant tissue) & $95 \%$ confidence interval $^{\mathrm{a}}$ & P-value ${ }^{a}$ \\
\hline$A K T 1$ & 0.73 & $(0.63-0.83)$ & $<0.001^{\mathrm{b}}$ \\
\hline$A R A F$ & 0.72 & $(0.63-0.81)$ & $<0.001^{\mathrm{b}}$ \\
\hline$B R A F$ & 0.84 & $(0.74-0.93)$ & 0.001 \\
\hline$G R B 2^{\mathrm{c}}$ & 1.37 & $(1.04-1.69)$ & $<0.001^{\mathrm{b}}$ \\
\hline$K R A S^{\mathrm{c}}$ & 2.04 & $(1.67-2.41)$ & $<0.001^{\mathrm{b}}$ \\
\hline$M A P 2 K 2$ & 0.64 & $(0.46-0.82)$ & $<0.001^{\mathrm{b}}$ \\
\hline$M A P 2 K 7$ & 0.52 & $(0.39-0.65)$ & $<0.001^{\mathrm{b}}$ \\
\hline$M A P 3 K 1$ & 0.85 & $(0.75-0.95)$ & 0.010 \\
\hline$M A P 3 K 2^{\mathrm{c}}$ & 1.24 & $(1.13-1.36)$ & $<0.001^{\mathrm{b}}$ \\
\hline$M A P 3 K 7^{\mathrm{c}}$ & 1.28 & $(1.14-1.41)$ & $<0.001^{\mathrm{b}}$ \\
\hline$M A P K 1$ & 0.77 & $(0.59-0.94)$ & $<0.001^{\mathrm{b}}$ \\
\hline$M A P K 14^{\mathrm{c}}$ & 1.27 & $(1.14-1.40)$ & $<0.001^{\mathrm{b}}$ \\
\hline$M A P K 3^{\mathrm{c}}$ & 1.71 & $(1.26-2.15)$ & $<0.001^{\mathrm{b}}$ \\
\hline$M A P K 7^{\mathrm{c}}$ & 1.20 & $(1.01-1.38)$ & 0.006 \\
\hline МАРК 8 & 0.81 & $(0.74-0.88)$ & $<0.001^{\mathrm{b}}$ \\
\hline МАРК & 0.47 & $(0.38-0.55)$ & $<0.001^{\mathrm{b}}$ \\
\hline$M K N K 1$ & 0.31 & $(0.25-0.38)$ & $<0.001^{\mathrm{b}}$ \\
\hline$M K N K 2$ & 0.35 & $(0.26-0.44)$ & $<0.001^{\mathrm{b}}$ \\
\hline$P A K 1^{\mathrm{c}}$ & 1.27 & $(1.08-1.45)$ & 0.001 \\
\hline$P D P K 1$ & 0.73 & $(0.64-0.81)$ & $<0.001^{\mathrm{b}}$ \\
\hline$P I K 3 C A^{\mathrm{c}}$ & 1.46 & $(1.25-1.68)$ & $<0.001^{\mathrm{b}}$ \\
\hline$P I K 3 C G^{\mathrm{c}}$ & 2.22 & $(1.61-2.82)$ & $<0.001^{\mathrm{b}}$ \\
\hline$P L K 3^{\mathrm{c}}$ & 1.56 & $(1.23-1.88)$ & $<0.001^{\mathrm{b}}$ \\
\hline$P T E N^{\mathrm{c}}$ & 1.29 & $(1.05-1.53)$ & 0.006 \\
\hline$P T K 2 B^{\mathrm{c}}$ & 1.68 & $(1.44-1.91)$ & $<0.001^{\mathrm{b}}$ \\
\hline$R A C 1^{\mathrm{c}}$ & 1.65 & $(1.34-1.96)$ & $<0.001^{\mathrm{b}}$ \\
\hline$R A F 1$ & 0.62 & $(0.54-0.69)$ & $<0.001^{\mathrm{b}}$ \\
\hline$R A L A^{\mathrm{c}}$ & 1.43 & $(1.27-1.59)$ & $<0.001^{\mathrm{b}}$ \\
\hline$R A L B P 1^{\mathrm{c}}$ & 1.60 & $(1.39-1.81)$ & $<0.001^{\mathrm{b}}$ \\
\hline$R A P I A^{\mathrm{c}}$ & 1.18 & $(1.07-1.29)$ & $<0.001^{\mathrm{b}}$ \\
\hline$R A S A I^{\mathrm{c}}$ & 1.28 & $(1.12-1.43)$ & $<0.001^{\mathrm{b}}$ \\
\hline$R A S A 2^{\mathrm{c}}$ & 1.87 & $(1.51-2.23)$ & $<0.001^{\mathrm{b}}$ \\
\hline$R H O A^{\mathrm{c}}$ & 1.23 & $(1.13-1.34)$ & $<0.001^{\mathrm{b}}$ \\
\hline$R I N 1^{\mathrm{c}}$ & 1.39 & (1.10-1.67) & 0.002 \\
\hline RPS6KA2 & 0.65 & $(0.49-0.81)$ & $0.001^{b}$ \\
\hline$R P S 6 K A 4^{c}$ & 1.76 & $(1.45-2.08)$ & $<0.001^{\mathrm{b}}$ \\
\hline$S H C 1^{\mathrm{c}}$ & 1.24 & $(1.09-1.38)$ & $0.001^{\mathrm{b}}$ \\
\hline$S O S 1^{\mathrm{c}}$ & 1.32 & $(1.14-1.50)$ & $<0.001^{\mathrm{b}}$ \\
\hline SOS2 & 0.68 & $(0.59-0.77)$ & $<0.001^{\mathrm{b}}$ \\
\hline$S R C^{\mathrm{c}}$ & 1.43 & $(1.16-1.71)$ & $<0.001^{\mathrm{b}}$ \\
\hline
\end{tabular}

${ }^{\mathrm{a}}$ Fold-change, 95\% confidence interval and P-values were calculated using RT ${ }^{2}$ Profiler PCR Assay Data analysis v3.5 program; ${ }^{\mathrm{b}}$ result that passed Bonferroni's correction for 52 analyzed genes (cut off $\mathrm{P}=0.001$ ); ' ${ }^{c}$ upregulated genes. There were 14 additional genes whose expression was not statistically significantly changed and that are therefore not listed in the table: AKT2, GSK3B, MAP2K1, MAP $3 K 4, M A P K 10, M T O R$, PRKACA, PRKCA, PTEN, PTK2, RALGDS, RAP1A, RPS6KA and STAT3.

the 52 analyzed genes $[B R A F$, mitogen-activated protein kinase kinase kinase 4 , mitogen-activated protein kinase 8 , MKNK1 and son of sevenless, Drosophila, homolog 2 (SOS2; $\mathrm{P}<0.05$; Table IV)], but none of these associations passed the threshold for the multiple testing correction. The expression profiles of the KRAS signaling pathway as a whole also did not significantly differ between KRAS wild-type and KRAS-mutated tumors (Fig. 3). 
Table IV. Downregulation of KRAS pathway genes in PDAC KRAS-mutated tumors compared with cases with wild-type $K R A S$.

\begin{tabular}{lccr}
\hline Gene & Fold-change $^{\mathrm{a}}$ (tumor vs. non-tumor) & 95\% confidence interval & P-value $^{\mathrm{a}}$ \\
\hline BRAF & 0.84 & $(0.72-0.95)$ & 0.021 \\
MAP3K4 & 0.79 & $(0.67-0.91)$ & 0.035 \\
MAPK8 & 0.84 & $(0.71-0.97)$ & 0.027 \\
MKNK1 & 0.72 & $(0.45-0.99)$ & 0.033 \\
SOS2 & 0.77 & $(0.59-0.94)$ & 0.003 \\
\hline
\end{tabular}

${ }^{\mathrm{a}}$ Fold-change, 95\% confidence interval and P-values were calculated using RT ${ }^{2}$ Profiler PCR Assay Data analysis v3.5 program.

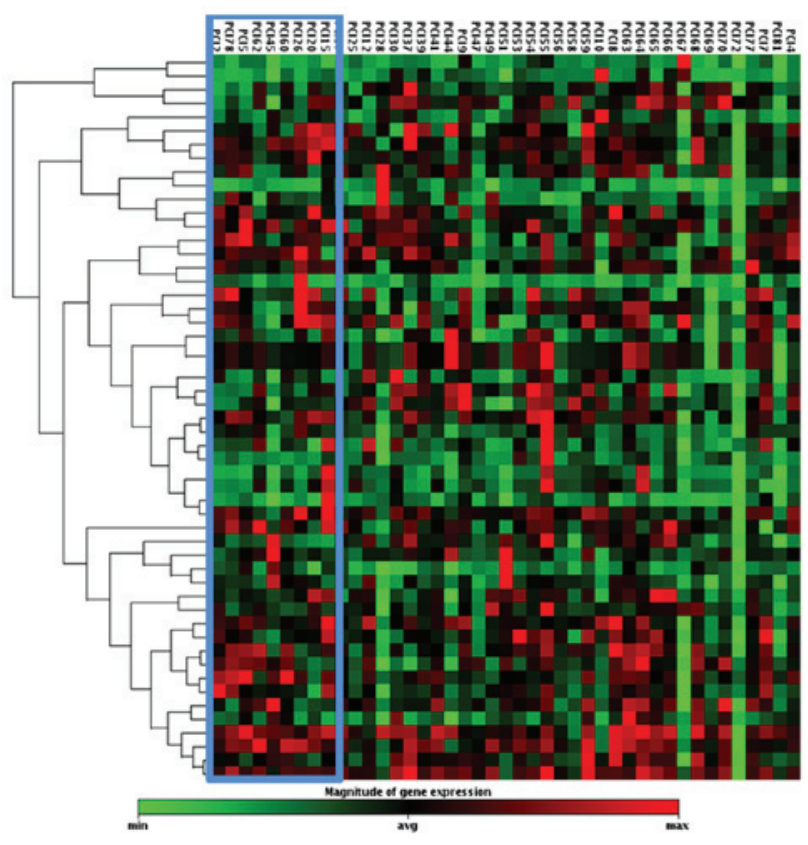

Figure 3. Heat map of KRAS signaling pathway expression profile of $K R A S$-mutated pancreatic ductal adenocarcinoma. KRAS wild-type tumors are marked by the blue box on the left and the samples harboring KRAS mutations are on the right. KRAS, KRAS proto-oncogene, GTPase.

KRAS mutation status had no significant effect on the OS time of the PDAC patients. KRAS wild-type patients experienced a median OS time of 22.3 months, and patients with KRAS mutation experienced a median OS time of 21.0 months $(\mathrm{P}=0.182)$.

There was also no association between $K R A S$ mRNA transcript levels and OS time. In contrast to the rest of pathway, $R A F 1$ showed a significant association with the OS time of the PDAC patients. Patients with $R A F 1$ expression levels lower than the median experienced longer OS times than patients with higher $R A F 1$ expression levels ( $\mathrm{P}=0.030)$ (Fig. 4). However, this association did not pass Bonferroni correction for multiple testing.

\section{Discussion}

Mutation analysis of the present cohort of patients with operable PDAC aligns with that of prior studies reporting the presence of KRAS mutation in the majority of PDAC cases $(18,19)$. Additionally, the genes of four KRAS downstream signaling

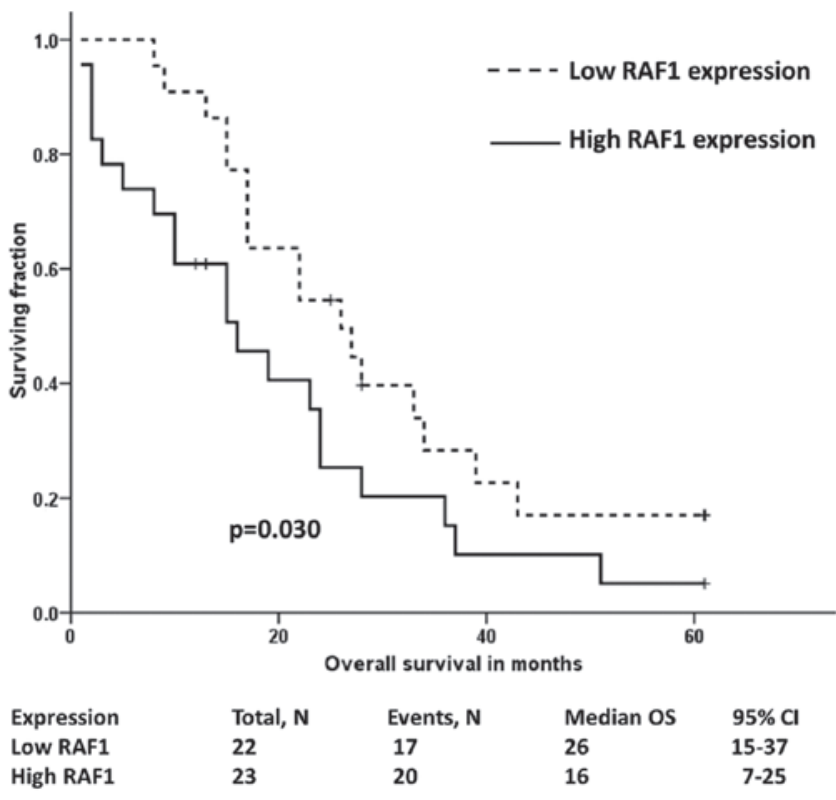

Figure 4. Kaplan-Meier survival plot presenting the correlation between $R A F 1$ expression and OS. RAF1, V-RAF-1 murine leukemia viral oncogene homolog 1; OS, overall survival; CI, confidence interval.

pathways, including the $P I 3 K / P D K 1 / A K T, R A L$ guanine nucleotide exchange factor, RINI/ABL and RAF/MAPK pathways, exhibited differential expression in PDAC compared with that of the adjacent normal tissues, although no significant differences were observed in the expression of these genes between patients with $K R A S$-mutated and wild-type tumors. The expression profiles of KRAS downstream signaling pathways were not associated with pathological characteristics that reflect tumor biology, including angioinvasion, perineural invasion, grade or presence of lymph node metastasis.

Similar to earlier studies (20-22), the present data indicated that in this cohort of patients (with early-stage disease and following radical surgery) the presence of a KRAS mutation had no effect on the OS time of the patients, although there was limited power to determine associations indicating more minor effects due to the limited size of the patient cohort. Moreover, with the exception of RAF1, no impact was observed of the expression profile of the KRAS downstream major effective signaling pathways on OS. These findings may explain why all previous efforts targeting KRAS failed to improve the patient outcome. 
Despite sustained efforts in preclinical and clinical research, PDAC remains a malignancy with an almost uniformly fatal prognosis (23). In contrast to other solid tumors, there has been no major progress in the systemic therapy of PDAC during the last decade. In particular, there is currently no targeted agent with clinically significant activity against this tumor.

Although molecular biomarkers play a crucial role in the management of numerous solid tumors (24), there are currently no useful biomarkers for treatment selection in PDAC. In recent years, a number of negative trials of targeted therapy have been conducted in PDAC $(25,26)$. Consequently, there is an urgent requirement to improve the understanding of PDAC pathogenesis and biology in order to identify novel therapeutic approaches and to define subgroups of patients for tailored therapies. It has been demonstrated that KRAS mutations represent the driver mutations in the majority of PDAC cases. KRAS-targeted agents can be classified into several categories according to the mechanism of action, namely small-molecule RAS-binding ligands, inhibitors of KRAS membrane anchorage, inhibitors that bind to RAS-binding domains of RAS-effector proteins and inhibitors of KRAS expression (27). However, attempts to therapeutically target KRAS or the downstream pathways have all thus far failed in clinical trials (28-32).

In conclusion, as expected, KRAS was mutated in the majority of PDAC cases. The genes of the KRAS downstream signaling pathways, including the $P I 3 K / P D K 1 / A K T$, $R A L$ guanine nucleotide exchange factor, $R I N 1 / A B L$ and $R A F / M A P K$ pathways, were differentially expressed in PDAC compared with those in adjacent non-neoplastic tissues. However, neither the presence of KRAS mutation nor the extent of KRAS signaling dysregulation was associated with OS time. Among the KRAS downstream signaling pathway genes investigated, only $R A F 1$ expression was predictive of outcome. It is possible that the analysis of post-transcriptional and epigenetic factors associated with KRAS signaling may shed more light onto the molecular biology of PDAC.

\section{Acknowledgements}

This study was supported by projects of the Czech Science Foundation (grant no. P301/12/1734), the Ministry of Health of the Czech Republic (grant no. 16-28375A), the Ministry of Education Youth and Sports of the Czech Republic (no. LO1503) and the Czech Ministry of Education (nos. NPU I LO1304 and RVO 61989592).

\section{References}

1. Siegel RL, Miller KD and Jemal A: Cancer statistics, 2015. CA Cancer J Clin 65: 5-29, 2015.

2. Conroy T, Desseigne F, Ychou M, Bouché O, Guimbaud R, Bécouarn Y, Adenis A, Raoul JL, Gourgou-Bourgade S, de la Fouchardière $\mathrm{C}$, et al: FOLFIRINOX versus gemcitabine for metastatic pancreatic cancer. N Engl J Med 364: 1817-1825, 2011.

3. Morris JP IV, Wang SC and Hebrok M: KRAS, hedgehog, Wnt and the twisted developmental biology of pancreatic ductal adenocarcinoma. Nat Rev Cancer 10: 683-695, 2010.

4. Pylayeva-Gupta Y, Grabocka E and Bar-Sagi D: RAS oncogenes: Weaving a tumorigenic web. Nat Rev Cancer 11: 761-774, 2011.

5. Eser S, Schnieke A, Schneider G and Saur D: Oncogenic KRAS signalling in pancreatic cancer. Br J Cancer 111: 817-822, 2014.
6. Eser S, Reiff N, Messer M, Seidler B, Gottschalk K, Dobler M, Hieber M, Arbeiter A, Klein S, Kong B, et al: Selective requirement of PI3K/PDK1 signaling for Kras oncogene-driven pancreatic cell plasticity and cancer. Cancer Cell 23: 406-420, 2013.

7. Collisson EA, Trejo CL, Silva JM, Gu S, Korkola JE, Heiser LM, Charles RP, Rabinovich BA, Hann B, Dankort D, et al: A central role for $\mathrm{RAF} \rightarrow \mathrm{MEK} \rightarrow \mathrm{ERK}$ signaling in the genesis of pancreatic ductal adenocarcinoma. Cancer Discov 2: 685-693, 2012

8. Lim KH, Baines AT, Fiordalisi JJ, Shipitsin M, Feig LA, Cox AD, Der CJ and Counter CM: Activation of RalA is critical for Ras-induced tumorigenesis of human cells. Cancer Cell 7: 533-545, 2005.

9. Feldmann G, Mishra A, Hong SM, Bisht S, Strock CJ, Ball DW, Goggins M, Maitra A and Nelkin BD: Inhibiting the cyclin-dependent kinase CDK5 blocks pancreatic cancer formation and progression through the suppression of Ras-Ral signaling. Cancer Res 70: 4460-4469, 2010.

10. Dhaka A, Costa RM, Hu H, Irvin DK, Patel A, Kornblum HI, Silva AJ, O'Dell TJ and Colicelli J: The RAS effector RIN1 modulates the formation of aversive memories. J Neurosci 23: 748-757, 2003.

11. Mohelnikova-Duchonova B, Kocik M, Duchonova B, Brynychova V, Oliverius M, Hlavsa J, Honsova E, Mazanec J, Kala Z, Ojima I, et al: Hedgehog pathway overexpression in pancreatic cancer is abrogated by new-generation taxoid SB-T-1216. Pharmacogenomics J: Aug 30, 2016 (Epub ahead of print).

12. Mohelnikova-Duchonova B, Brynychova V, Hlavac V, Kocik M, Oliverius M, Hlavsa J, Honsova E, Mazanec J, Kala Z, Melichar B and Soucek P: The association between the expression of solute carrier transporters and the prognosis of pancreatic cancer. Cancer Chemother Pharmacol 72: 669-682, 2013.

13. Mohelnikova-Duchonova B, Brynychova V, Oliverius $M$ Honsova E, Kala Z, Muckova K and Soucek P: Differences in transcript levels of ABC transporters between pancreatic adenocarcinoma and nonneoplastic tissues. Pancreas 42: 707-716, 2013.

14. Soucek P, Anzenbacher P, Skoumalova I and Dvorak M: Expression of cytochrome $\mathrm{P} 450$ genes in $\mathrm{CD}_{3} 4^{+}$hematopoietic stem and progenitor cells. Stem Cells 23: 1417-1422, 2005.

15. Mohelnikova-Duchonova B, Oliverius M, Honsova E and Soucek P: Evaluation of reference genes and normalization strategy for quantitative real-time PCR in human pancreatic carcinoma. Dis Markers 32: 203-210, 2012.

16. Bustin SA, Benes V, Garson JA, Hellemans J, Huggett J, Kubista M, Mueller R, Nolan T, Pfaffl MW, Shipley GL, et al: The MIQE guidelines: Minimum information for publication of quantitative real-time PCR experiments. Clin Chem 55: 611-622, 2009.

17. Livak KJ and Schmittgen TD: Analysis of relative gene expression data using real-time quantitative PCR and the 2(-Delta Delta C(T)) method. Methods 25: 402-408, 2001.

18. Caldas C, Hahn SA, Hruban RH, Redston MS, Yeo CJ and Kern SE: Detection of K-ras mutations inthe stool of patients with pancreatic adenocarcinoma and pancreatic ductal hyperplasia. Cancer Res 54: 3568-3573, 1994.

19. Bournet B, Buscail C, Muscari F, Cordelier P and Buscail L: Targeting KRAS for diagnosis, prognosis, and treatment of pancreatic cancer: Hopes and realities. Eur J Cancer 54: 75-83, 2016.

20. Zhou L, Baba Y, Kitano Y, Miyake K, Zhang X, Yamamura K, Kosumi K, Kaida T, Arima K, Taki K, et al: KRAS, BRAF, and PIK3CA mutations, and patient prognosis in 126 pancreatic cancers: Pyrosequencing technology and literature review. Med Oncol 33: 32, 2016.

21. Oliveira-Cunha M, Hadfield KD, Siriwardena AK and Newman W: EGFR and KRAS mutational analysis and their correlation to survival in pancreatic and periampullary cancer. Pancreas 41: 428-434, 2012.

22. Schultz NA, Roslind A, Christensen IJ, Horn T, Høgdall E, Pedersen LN, Kruhøffer M, Burcharth F, Wøjdemann M and Johansen JS: Frequencies and prognostic role of KRAS and BRAF mutations in patients with localized pancreatic and ampullary adenocarcinomas. Pancreas 41: 759-766, 2012.

23. Lemstrova R, Melichar B and Mohelnikova-Duchonova B: Therapeutic potential of taxanes in the treatment of metastatic pancreatic cancer. Cancer Chemother Pharmacol 78: 1101-1111, 2016.

24. Melichar B: Laboratory medicine and medical oncology: The tale of two Cinderellas. Clin Chem Lab Med 51: 99-112, 2013. 
25. Fuchs CS, Azevedo S, Okusaka T, Van Laethem JL, Lipton LR, Riess H, Szczylik C, Moore MJ, Peeters M and Bodoky G: A phase 3 randomized, double-blind, placebo-controlled trial of ganitumab or placebo in combination with gemcitabine as first-line therapy for metastatic adenocarcinoma of the pancreas: The GAMMA trial. Ann Oncol 26: 921-927, 2015.

26. Deplanque G, Demarchi M, Hebbar M, Flynn P, Melichar B, Atkins J, Nowara E, Moyé L, Piquemal D, Ritter D, et al: A randomized, placebo-controlled phase III trial of masitinib plus gemcitabine in the treatment of advanced pancreatic cancer. Ann Oncol 26: 1194-1200, 2015.

27. Chuang HC, Huang PH, Kulp SK and Chen CS: Pharmacological strategies to target oncogenic KRAS signaling in pancreatic cancer. Pharmacol Res 117: 370-376, 2017.

28. Chung V, McDonough S, Philip PA, Cardin D, Wang-Gillam A, Hui L, Tejani MA, Seery TE, Dy IA, Al Baghdadi T, et al: Effect of Selumetinib and MK-2206 vs oxaliplatin and fluorouracil in patients with metastatic pancreatic cancer after prior therapy: SWOG S1115 study randomized clinical trial. JAMA Oncol 3: 516-522, 2017.
29. Riely GJ, Johnson ML, Medina C, Rizvi NA, Miller VA, Kris MG, Pietanza MC, Azzoli CG, Krug LM, Pao W and Ginsberg MS: A phase II trial of Salirasib in patients with lung adenocarcinomas with KRAS mutations. J Thoracic Oncol 6: 1435-1437, 2011.

30. Karp JE, Vener TI, Raponi M, Ritchie EK, Smith BD, Gore SD, Morris LE, Feldman EJ, Greer JM, Malek S, et al: Multi-institutional phase 2 clinical and pharmacogenomic trial of tipifarnib plus etoposide for elderly adults with newly diagnosed acute myelogenous leukemia. Blood 119: 55-63, 2012.

31. Rao S, Cunningham D, de Gramont A, Scheithauer W, Smakal M, Humblet Y, Kourteva G, Iveson T, Andre T, Dostalova J, et al: Phase III double-blind placebo-controlled study of farnesyl transferase inhibitor R115777 in patients with refractory advanced colorectal cancer. J Clin Oncol 22: 3950-3957, 2004.

32. Van CE, van de Velde H, Karasek P, Oettle H, Vervenne WL, Szawlowski A, Schoffski P, Post S, Verslype C, Neumann H, et al: Phase III trial of gemcitabine plus tipifarnib compared with gemcitabine plus placebo in advanced pancreatic cancer. J Clin Oncol 22: 1430-1438, 2004. 